\title{
On Enterprise Social Responsibility Comprehensive Evaluation Based on Two-Step Fuzzy Evaluation Method
}

\author{
Dongsheng Li, Qiulin Yang, Deqiang Yu \\ School of Economics and Management, University of South China, Hengyang, China \\ Email:1ds1010@sina.com
}

Received November 17, 2012; revised December 18, 2012; accepted January 12, 2013

\begin{abstract}
In order to evaluate the enterprise social responsibility scientifically, this paper constructed an enterprise social responsibility evaluation indexes system composed by five first class indexes (environmental protection, resources utilization, economic benefit, human resources and social contribution and so on) and 18 second indexes. The two-step fuzzy evaluation method was adopted to evaluate comprehensive effect and Wuhan Iron and Steel (Group) Corporation (WISCO) was given for example.
\end{abstract}

Keywords: Two-Oriented Society; Enterprise Social Responsibility; Two-Step Fuzzy Evaluation Method

\section{Introduction}

The "Two-oriented society" construction plan was put forward by the National Development and Reform Commission in December of 2007, and "Wuhan city circle" and "Changsha-Zhuzhou-Xiangtan city cluster" were conducted as the reform testing districts. It is of great significance to propel the sustainable development of city cluster as well as the solution of problem accompanying urbanization in the areas of resource and energy, ecological environment, and economic development model.

The "Two-oriented society" construction demands that the enterprise should utilize the limited resources reasonably, efficiently and circularly, at the same time corresponding environmental protection measures should be made to reduce the discharge of wastes pollution, to minimize the damage to the environment and to achieve harmonious coexistence of natural environment and economical society. The essence is that the enterprise should undertake social responsibilities more actively [1]. So, it is significance to scientifically evaluate the social responsibility fulfillment of enterprise.

Nowadays, the social responsibility standards have a broad impact on the society, which include of SA8000 social responsibility standard, the Dow Jones Sustainability Indexes (DJSI), G3 international sustainable development report guide and so on [2]. In our country, the famous ones are the social responsibility standard system of Chinese enterprise (HM3000), the top 100 enterprises social responsibility development indexes issued by the academy Chinese Academy of Social Sciences and the golden bee enterprise social responsibility list [3]. How- ever, all these evaluation systems do not set meticulous regulations to environment and resources responsibility, and the enterprise' qualitative evaluation basis can only be obtained from its incomplete information disclosure, which will induce the fulfillment of enterprise social responsibility can't be measured effectively. This paper mainly focuses on constructing the enterprise social responsibility evaluation indexes system based on "Twooriented society" by analyzing of the stakeholder theory, HM3000 and SA8000. The two-step fuzzy evaluation method is adopted to evaluate the fulfillment of enterprise social responsibility.

\section{The Construction of the Enterprise Social Responsibility Evaluation Indexes System Based on "Two-Oriented Society"}

In order to synthetically, comprehensively evaluate the fulfillment of enterprise social responsibility based on "Two-oriented society", resources and environment social responsibility are linked up with economic and social one of enterprise, in accordance with the scientific principle, systematic one, close to "Two-oriented society" one, quantitative one, independence one and comparable one. It will construct the enterprise social responsibility indexes system at two levels. According to the suggestions of eight university professors, six enterprise executives and six experts of government environmental protection department, combined with enterprise business characteristics, the first class indexes include five aspects, such as environmental protection, resources utilization, economic benefit, human resources and social contribu- 
tion. And the second class indexes consist of 18 ones, such as harmful gas emissions per ten thousand yuan RMB operating income (see Table 1).

\section{Two-Step Fuzzy Evaluation Method of Enterprise Social Responsibility}

This paper will use the modified analytic hierarchy process (MAHP) to calculate the index weight after the enterprise social responsibility evaluation indexes system has been established. Then, the composite score of enterprise social responsibility was calculated using two-step fuzzy evaluation method.

\subsection{Calculating Index Weight Based on the Modified Analytic Hierarchy Process}

After enterprise social responsibility evaluation indexes system was determined, it needs to calculate the weight of each index. There are many methods to ascertain the weight, of which analytic hierarchy process is an important one. Analytic hierarchy process is an evaluating method combined qualitative with quantitative analysis, which was put forward in the 1970's by A. L. Saaty [4]. This method decomposes the complex problem into several levels and several factors. Then, it will compare and calculate the factors simply to draw their weights and get the evaluation result. But this method has the defect in texting non consistency judgment matrix, for it needs artificial estimate adjustment and carrying on the multiple times if necessary.

In order to overcome this problem, a modified method of analytical hierarchy process is adopted. Its main characteristics are to introduce the quasi-optimal matrix, which can meet the consistency naturally and doesn't

Table 1. Enterprise social responsibility evaluation indexes system.

\begin{tabular}{|c|c|c|}
\hline First class indexes & Second class indexes & Meaning \\
\hline \multirow{5}{*}{ Environmental protection $B_{1}$} & $\begin{array}{l}\text { Harmful gas emissions per ten thousand yuan } \\
\text { RMB operating income } B_{11}\end{array}$ & $\begin{array}{l}\text { Harmful gas emissions per year/Operating income per year (ten } \\
\text { thousand yuan RMB) }\end{array}$ \\
\hline & $\begin{array}{l}\text { COD emissions per ten thousand yuan operating } \\
\text { income } B_{12}\end{array}$ & $\begin{array}{l}\text { COD emissions per year/Operating income per year (ten thousand } \\
\text { yuan RMB) }\end{array}$ \\
\hline & $\begin{array}{l}\text { Solid waste emissions per ten thousand yuan RMB } \\
\text { operating income } B_{13}\end{array}$ & Solid waste emissions/Ten thousand yuan RMB operating income \\
\hline & $\begin{array}{l}\text { Wastewater emissions per ten thousand yuan RMB } \\
\text { operating income } B_{14}\end{array}$ & $\begin{array}{l}\text { Wastewater emissions per year/Operating income per year (ten } \\
\text { thousand yuan RMB) }\end{array}$ \\
\hline & $\begin{array}{l}\text { Total expenditure accounts for the proportion of } \\
\text { profits per year } B_{15}\end{array}$ & $\begin{array}{l}\text { Environmental protection aggregate expenditure per year/Operating } \\
\text { profit per year (ten thousand yuan RMB) }\end{array}$ \\
\hline \multirow{5}{*}{ Resource utilization $B_{2}$} & $\begin{array}{l}\text { Comprehensive energy consumption per ten } \\
\text { thousand yuan RMB operating income } B_{21}\end{array}$ & $\begin{array}{l}\text { Comprehensive energy consumption (including coal, oil, electricity } \\
\text { etc.)/Operating income per year (ten thousand yuan RMB) }\end{array}$ \\
\hline & $\begin{array}{l}\text { New water consumption per ten thousand yuan } \\
\text { RMB operating income } B_{22}\end{array}$ & $\begin{array}{l}\text { New water consumption per year/Operating income per year (ten } \\
\text { thousand yuan RMB) }\end{array}$ \\
\hline & $\begin{array}{l}\text { Mineral resources consumption per ten thousand } \\
\text { yuan RMB operating income } B_{23}\end{array}$ & $\begin{array}{l}\text { Mineral resources per year/Operating income per year (ten } \\
\text { thousand yuan RMB) }\end{array}$ \\
\hline & Recycle rate of industrial solid waste $B_{24}$ & $\begin{array}{l}\text { (Recycle rate of industrial solid waste per year/total emissions of } \\
\text { industrial three wastes per year) } \times 100 \%\end{array}$ \\
\hline & Recycle rate of industrial wastewater $B_{25}$ & $\begin{array}{l}\text { (Recycle rate of industrial wastewater per year/Total waste per } \\
\text { year) } \times 100 \%\end{array}$ \\
\hline \multirow{3}{*}{ Economic benefit $B_{3}$} & Return on equity $B_{31}$ & After-tax profits per year/net asset \\
\hline & Sales increasing ratio $B_{32}$ & $\begin{array}{l}{[(\text { Current operating income }- \text { operating income last year }) /} \\
\text { Operating income last year }] \times 100 \%\end{array}$ \\
\hline & $\begin{array}{l}\text { Capital value-retaining and value-increasing rate } \\
B_{33}\end{array}$ & (Final total owners' equity/Initial total owners' equity) $\times 100 \% \mathrm{t}$ \\
\hline \multirow{2}{*}{ Human resources $B_{4}$} & $\begin{array}{l}\text { Annual staff and workers' training fees accounted } \\
\text { for the proportion of profit after tax } B_{41}\end{array}$ & Annual staff and workers' training fees/Annual profit after tax \\
\hline & Worker safety accident rate $B_{43}$ & $\begin{array}{l}\text { (The number of inductrial injury workers/Average number of listed } \\
\text { workers) } \times 1000\end{array}$ \\
\hline \multirow[t]{2}{*}{ Social contribution $B_{5}$} & Contribution rate to society $B_{51}$ & $\begin{array}{l}{[(\text { Expenses of average wages and welfare of staff }+ \text { interest }} \\
\text { expenses of net amount }+ \text { various taxes }+ \text { net profit }) / \text { Average total } \\
\text { assets }] \times 100 \%\end{array}$ \\
\hline & Donation rate to society $B_{52}$ & Annual external donation/Annual profit after tax \\
\hline
\end{tabular}


need consistent test $[5,6]$. The process of the modified analytic hierarchy process is as follows:

Firstly, it will construct judgment matrix, the method is the same of the one of analytic hierarchy process. Let the judgment matrix be $A$, then, $A$ can be represented as in (1).

$$
A=\left(a_{i j}\right)_{\times n}, a_{i j}=1 / a_{j i}, a_{i i}=1, i \neq j, i, j=1,2, \cdots, n
$$

Secondly, it will calculate the anti-symmetric matrix of judgment matrix $A$, and let it be $L$, it can be obtained by (2).

$$
L=\left(l_{i j}\right)_{\times n}, l_{i j=} \ln \left(a_{i j}\right), i \neq j, i, j=1,2, \cdots, n
$$

Thirdly, it will construct quasi-optimal matrix of this judgment matrix $A$, let it be $M$, it can be shown as in (3).

$$
\begin{aligned}
M & =\left(m_{i j}\right)_{n \times n}=\mathrm{e}^{f_{i j}}, \\
f_{i j} & =\sum_{k=1}^{n}\left(l_{i k}-l_{j k}\right) / n, i, j=1,2, \cdots, n
\end{aligned}
$$

The end, it will calculate eigenvector of $M$ by square root method. Let the eigenvector be $W$. And the component of $W$ (let to be $W_{i}$ ) is the weight of corresponding index, it can be gotten by (4).

$$
W_{i}=\frac{\sqrt[n]{M_{i}}}{\sum_{i=1}^{n} M_{i}}(i=1,2, \cdots, n)
$$

\subsection{Two-Step Fuzzy Evaluation Method}

Fuzzy evaluation method is a decision-making one for some objective under fuzzy environment, which considers the influence of many factors and can solve the problem of indexes system better. It can reduce the influence of the artificial factor to the smallest extent, and has the advantage over reflecting the nature of problem. The enterprise social responsibility evaluation indexes system is divided into three levels in this paper based on "Twooriented society", so, two-step fuzzy evaluation method was adopted.

\subsubsection{Elements}

\section{1) Factors set}

The factor set of enterprise social responsibility evaluation indexes system consists of the first class indexes set and the second class indexes set, as are showed in Table 1. The first class indexes set is $B=\left(B_{1}, B_{2}, B_{3}, B_{4}\right.$, $B_{5}$ ), and $B_{1}, B_{2}, B_{3}, B_{4}, B_{5}$ represent five first class indexes in the Table 1. $B_{i}=\left(B_{i 1}, B_{i 2}, \cdots, B_{i m}\right), i=1,2, \cdots, 5$. $B_{i 1}, B_{i 2}, \cdots, B_{i m}$ are the second indexes corresponding with the first class index $B_{i}$, which can also be seen in Table 1.

\section{2) Weight set}

The weight set of enterprise social responsibility evaluation indexes system includes the first class indexes weight set (let be $W_{B}$ ) and the second class indexes weight set (let be $\left.W_{i}=(i=1,2, \cdots, 5)\right)$. Let $W_{B}=\left(w_{B 1}, w_{B 2}\right.$, $\left.\cdots, w_{B 5}\right), W_{i}=\left(w_{i 1}, w_{i 2}, \cdots, w_{i m}\right) . W_{B}$ and $W_{i}$ are both determined by modified analytic hierarchy process.

\section{3) Comment set}

Let $V=\left(V_{1}, V_{2}, \cdots, V_{5}\right)$ to be a comment set, which stands by five grades, such as excellent, good, medium, poor and very poor.

\subsubsection{Fuzzy Relation from Membership Matrix to Comment Set}

Membership matrix $R$ is constructed to determine the fuzzy relation from $B$ to $V . R=\left(R_{1}, R_{2}, \cdots, R_{5}\right)^{\mathrm{T}}$, and $R_{i}$ is shown as in (5).

$$
R_{i}=\left[\begin{array}{ccccc}
r_{i 11} & r_{i 12} & r_{i 13} & r_{i 14} & r_{i 15} \\
r_{i 21} & r_{i 22} & r_{i 23} & r_{i 24} & r_{i 25} \\
\cdots & \ldots & \ldots & \ldots & \ldots \\
r_{i m 1} & r_{i m 2} & r_{i m 3} & r_{i m 4} & r_{i m 5}
\end{array}\right]
$$

In the equation, $R_{i}(i=1,2, \cdots, 5)$ is the membership matrix of the ith first class index, and $m$ is its index number, while $r_{i l j}(i=1,2, \cdots, 5 ; j=1,2, \cdots, 5)$ represent the membership degree of grade $j(j=1,2, \cdots, 5)$ corresponding its lth second index. The value of $r_{i m j}$ is divided into positive index (the bigger, the better) and reverse index (the smaller, the better) according to its property. They are calculated as follows:

1) The calculation of membership degree of positive index

Positive indexes are ranked in the order from big to small, the bigger the index value, the better the membership, which indicates the enterprise complete well. The calculation of membership degree of positive index is as follows:

Firstly, if the actual value of the lth second index $X_{i l}$ is greater than its corresponding "excellent" grade standard value, then the membership to "excellent" is 1 , and the ones to the other four is 0 . That is, if $X_{i l}>V_{i l}$, then

$$
r_{i l 1}=1, r_{i l 2}=r_{i l 3}=r_{i l 4}=r_{i l 5}=0
$$

Secondly, if the actual value of the lth second index $X_{i l}$ is between the $j$ th grade and the $(j+1)$ th one, that is, $V_{i l(j+1)} \leq X_{i l} \leq V_{i l j}$, then the membership to $(j+1)$ th grade is shown as in (6).

$$
r_{i l(j+1)}=\frac{V_{i l j}-X_{i l}}{V_{i l j}-V_{i l(j+1)}}, j=0,1,2,3,4
$$

The membership to the $j t h$ grade is shown as in (7).

$$
r_{i m j}=1-r_{i m(j+1)}, j=0,1,2,3,4
$$

The membership to other three grades is 0 . 
Thirdly, if the actual value of the lth second index $X_{i l}$ is less than its corresponding "very poor" grade standard value, then the membership to "very poor" for is 1 , and the ones to others are 0 . That is, when $X_{i l}<V_{i l}$,

$$
r_{i l 5}=1 ; r_{i l 1}=r_{i l 2}=r_{i l 3}=r_{i l 4}=0
$$

\section{2) The calculation of membership degree of reverse index}

Reverse indexes are ranked in the order from small to big, the smaller the index value, the better the membership. The calculation of membership degree of reverse index is similar to positive ones.

\subsection{Hierarchical Fuzzy Evaluation Method}

The enterprise social responsibility indexes evaluation system based on "Two-oriented society" is divided into three layers, such as the target layer, the first class index layer and the second class one. So, it can be evaluated by two-step fuzzy evaluating method. The first step is the evaluation of second class index layer to the first class one, and the second step is the first class index layer to the target layer.

The fuzzy evaluation matrix of second class index layer to the first class one is

$$
C=\left\{C_{1}, C_{2}, \cdots, C_{5}\right\}^{\mathrm{T}}
$$

$C_{i}(i=1,2, \cdots, 5)$ is shown as in (8).

$$
C_{i}=W_{i} \circ R_{i}=\left(C_{i 1}, C_{i 2}, \cdots, C_{i m}\right)
$$

The fuzzy evaluation of the first class index layer to the target layer is $S, S$ can be obtained by (9).

$$
S=W_{B} \circ C=\left(S_{1}, S_{2}, S_{3}, S_{4}, S_{5}\right)
$$

In (2.9), $S_{j}, j=1,2, \cdots, 5$ is the comprehensive performance of the membership degree to the $j$ th grade. If

$$
\sum_{j=1}^{5} S_{j} \neq 1
$$

normalization process will be necessary. Let the new matrix after normalization process is $P=\left(P_{1}, P_{2}, P_{3}, P_{4}\right.$, $\left.P_{5}\right) . P_{i}(i=1,2,3,4,5)$ is shown as in (10).

$$
P_{i}=S_{i} / \sum_{i=1}^{5} S_{i}
$$

According to the maximum membership degree principle, $\max _{1 \leq j \leq 5}\left\{P_{j}\right\}$ is chosen to refer as evaluation result of the ith first class index.

\section{Case Study}

In order to expound how to use the two-steps fuzzy synthesize evaluation method to estimate the enterprise social responsibility, an example is given. It will take $\mathrm{Wu}-$ han Iron and Steel (Group) Corp. (WISCO) for example.

\subsection{Data Source}

The data mainly come from the social responsibility report in 2008 and the annual report in 2007 of WISCO. The secondary indexes were calculated as Table 2 .

\subsection{The Evaluation Standard Value}

The evaluation standard value for each second index is shown in Table $\mathbf{3}$ according to the published standards and the actual situation.

\subsection{The Weights of Indexes System}

By virtue of survey results of eight university professors, six enterprise executives and six experts of government environmental protection department, the judgment matrix of the first class indexes and the second class ones are shown as (11)-(16). $A$ is the judgment matrix of the first class index $B, B=\left(B_{1}, B_{2}, B_{3}, B_{4}, B_{5}\right)$, and $A_{i}(i=1$, $2, \cdots, 5)$ is the judgment matrix of $B_{i}, B_{i}=\left(B_{i 1}, B_{i 2}, \cdots\right.$, $B_{\text {im }}$.

$$
\begin{aligned}
& A=\left[\begin{array}{ccccc}
1 & 3 & 1 & 2 & 5 \\
1 / 3 & 1 & 1 & 2 & 6 \\
1 & 1 & 1 & 2 & 4 \\
1 / 2 & 1 / 2 & 1 / 2 & 1 & 1 \\
1 / 5 & 1 / 6 & 1 / 4 & 1 & 1
\end{array}\right] \\
& A_{1}=\left[\begin{array}{ccccc}
1 & 3 & 3 & 3 & 2 \\
1 / 3 & 1 & 3 & 1 / 2 & 3 \\
1 / 3 & 1 / 3 & 1 & 1 / 2 & 1 \\
1 / 3 & 2 & 2 & 1 & 1 \\
1 / 2 & 1 / 3 & 1 & 1 & 1
\end{array}\right] \\
& A_{2}=\left[\begin{array}{ccccc}
1 & 3 & 1 / 2 & 3 & 3 \\
1 / 3 & 1 & 1 / 3 & 1 / 2 & 2 \\
2 & 3 & 1 & 3 & 3 \\
1 / 3 & 2 & 1 / 3 & 1 & 3 \\
1 / 3 & 1 / 2 & 1 / 3 & 1 / 3 & 1
\end{array}\right] \\
& A_{3}=\left[\begin{array}{ccc}
1 & 4 & 1 / 3 \\
1 / 4 & 1 & 1 / 6 \\
3 & 6 & 1
\end{array}\right] \\
& A_{4}=\left[\begin{array}{ccc}
1 & 3 & 1 / 2 \\
1 / 3 & 1 & 1 / 5 \\
2 & 5 & 1
\end{array}\right] \\
& A_{5}=\left[\begin{array}{cc}
1 & 1 / 3 \\
3 & 1
\end{array}\right]
\end{aligned}
$$


Table 2. The actual value of social responsibility indexes of WISCO.

\begin{tabular}{|c|c|c|c|}
\hline Second class indexes code & Actual value code & Unit & Actual value \\
\hline$B_{11}$ & $X_{11}$ & Kilogram/ten thousand yuan RMB & 2.3573 \\
\hline$B_{12}$ & $X_{12}$ & Kilogram/ten thousand yuan RMB & 0.1164 \\
\hline$B_{13}$ & $X_{13}$ & ton/ten thousand yuan RMB & 0.7304 \\
\hline$B_{14}$ & $X_{14}$ & ton/ten thousand yuan RMB & 2.3275 \\
\hline$B_{15}$ & $X_{15}$ & $\%$ & 5.3 \\
\hline$B_{21}$ & $X_{21}$ & $\%$ & 10.08 \\
\hline$B_{22}$ & $X_{22}$ & ton/ten thousand yuan RMB & 7.5792 \\
\hline$B_{23}$ & $X_{23}$ & ton/ten thousand yuan RMB & 1.61 \\
\hline$B_{24}$ & $X_{24}$ & $\%$ & 22.67 \\
\hline$B_{25}$ & $X_{25}$ & $\%$ & 97 \\
\hline$B_{31}$ & $X_{31}$ & $\%$ & 14.37 \\
\hline$B_{32}$ & $X_{32}$ & $\%$ & 17.97 \\
\hline$B_{33}$ & $X_{33}$ & $\%$ & 8.88 \\
\hline$B_{41}$ & $X_{41}$ & class & 102 \\
\hline$B_{42}$ & $X_{42}$ & $\%$ & 20.2 \\
\hline$B_{43}$ & $X_{43}$ & $\%$ & 0.5 \\
\hline$B_{51}$ & $X_{51}$ & $\%$ & 19.86 \\
\hline$B_{52}$ & $X_{52}$ & $\%$ & 0.47 \\
\hline
\end{tabular}

Table 3. The evaluation standard value of second indexes.

\begin{tabular}{|c|c|c|c|c|c|c|}
\hline \multirow{2}{*}{ Second class indexes code } & \multirow{2}{*}{ Unit and standard value code } & \multicolumn{5}{|c|}{ Evaluation level } \\
\hline & & Excellence & Good & Medium & Poor & Very poor \\
\hline$B_{11}$ & Kilogram/ten thousand yuan RMB, $V_{11}$ & $<2.0$ & $2.0-2.5$ & $2.5-3$ & $3-3.5$ & $>3.5$ \\
\hline$B_{12}$ & Kilogram/ten thousand yuan RMB, $V_{12}$ & $<0.1$ & $0.1-0.2$ & $0.2-0.3$ & $0.3-0.4$ & $>0.4$ \\
\hline$B_{13}$ & ton/ten thousand yuan RMB, $V_{13}$ & $<0.3$ & $0.3-0.5$ & $0.5-0.7$ & $0.7-0.9$ & $>0.9$ \\
\hline$B_{14}$ & ton/ten thousand yuan RMB, $V_{14}$ & $<0.5$ & $0.5-1.0$ & $1.0-1.5$ & $1.5-2$ & $>2.0$ \\
\hline$B_{15}$ & $\%, V_{15}$ & $>5$ & $4-5$ & $3-4$ & $2-3$ & $<2.0$ \\
\hline$B_{21}$ & $\%, V_{21}$ & $>10$ & $8-10$ & $6-8$ & $4-6$ & $<4.0$ \\
\hline$B_{22}$ & ton/ten thousand yuan RMB, $V_{22}$ & $<5$ & $5-7$ & $7-9$ & $9-11$ & $>11$ \\
\hline$B_{23}$ & ton/ten thousand yuan RMB, $V_{23}$ & $<0.5$ & $0.5-1.0$ & $1.0-1.5$ & $1.5-2.0$ & $>2.0$ \\
\hline$B_{24}$ & $\%, V_{24}$ & $>20$ & $15-20$ & $10-15$ & $5-10$ & $<5.0$ \\
\hline$B_{25}$ & $\%, V_{25}$ & $>80$ & $60-80$ & $40-60$ & $20-40$ & $<20$ \\
\hline$B_{31}$ & $\%, V_{31}$ & $>30$ & $20-30$ & $10-20$ & $5-10$ & $<5.0$ \\
\hline$B_{32}$ & $\%, V_{32}$ & $>20$ & $15-20$ & $10-15$ & $5-10$ & $<5.0$ \\
\hline$B_{33}$ & $\%, V_{33}$ & $>20$ & $15-20$ & $10-15$ & $5-10$ & $<5.0$ \\
\hline$B_{41}$ & Class, $V_{41}$ & $>50$ & $40-50$ & $30-40$ & $20-30$ & $<20$ \\
\hline$B_{42}$ & $\%, V_{42}$ & $>20$ & $15-20$ & $10-15$ & $5-10$ & $<5.0$ \\
\hline$B_{43}$ & $\%, V_{43}$ & $<0.3$ & $0.3-0.4$ & $0.4-0.5$ & $0.5-0.6$ & $>0.6$ \\
\hline$B_{51}$ & $\%, V_{51}$ & $>20$ & $15-20$ & $10-15$ & $5-10$ & $<5.0$ \\
\hline$B_{52}$ & $\%, V_{52}$ & 3 & $2-3$ & $1-2$ & $0.5-1$ & $>0.5$ \\
\hline
\end{tabular}


The weight sets of he first class indexes and the second class ones are obtained by modified analytic hierarchy process, which are shown as in (17) and (18).

$$
\begin{aligned}
& W_{B}=\left(\begin{array}{lllll}
W_{B_{1}} & W_{B_{2}} & W_{B_{3}} & W_{B_{4}} & W_{B_{5}}
\end{array}\right) \\
& =\left(\begin{array}{lllll}
0.3373 & 0.2254 & 0.2590 & 0.1127 & 0.0656
\end{array}\right) \\
& W_{1}=\left(\begin{array}{lllll}
W_{11} & W_{12} & W_{13} & W_{14} & W_{15}
\end{array}\right) \\
& =\left(\begin{array}{lllll}
0.3949 & 0.1929 & 0.0996 & 0.1884 & 0.1243
\end{array}\right) \\
& W_{2}=\left(\begin{array}{lllll}
W_{21} & W_{22} & W_{23} & W_{24} & W_{25}
\end{array}\right) \\
& =\left(\begin{array}{lllll}
0.2843 & 0.1088 & 0.3751 & 0.1558 & 0.0761
\end{array}\right) \\
& W_{3}=\left(\begin{array}{lll}
W_{31} & W_{32} & W_{33}
\end{array}\right)=\left(\begin{array}{lll}
0.2706 & 0.0852 & 0.6442
\end{array}\right)(18) \\
& W_{4}=\left(\begin{array}{lll}
W_{41} & W_{42} & W_{43}
\end{array}\right)=\left(\begin{array}{lll}
0.3090 & 0.1095 & 0.5816
\end{array}\right) \\
& W_{5}=\left(\begin{array}{ll}
W_{51} & W_{52}
\end{array}\right)=\left(\begin{array}{ll}
0.2500 & 0.7500
\end{array}\right)
\end{aligned}
$$

\subsection{The Results}

Membership degrees to the second class indexes are cal- culated as shown in Table 4. And the evaluation result of first class indexes is shown in Table 5, according to the two-step fuzzy evaluation method.

1) The fulfillment of the second class indexes of WISCO

From Table 4, what can be seen that the fulfillment of the second class indexes of WISCO in 2008 was well. "Total expenditure accounts for the proportion of profits per year", "Comprehensive energy consumption per ten thousand yuan RMB operating income", "Recycle rate of industrial wastewater" and "Annual staff and workers' training classes" are "excellence". "COD emissions per ten thousand yuan RMB operating income" and "Recycle

\begin{tabular}{|c|c|c|c|c|c|c|}
\hline \multirow{2}{*}{ The second class indexes code } & \multirow{2}{*}{ Fuzzy evaluation matrix code } & \multicolumn{5}{|c|}{ Membership degree } \\
\hline & & Excellence & Good & Medium & Poor & Very poor \\
\hline$B_{11}$ & $C_{11}$ & 0.29 & 0.71 & 0 & 0 & 0 \\
\hline$B_{12}$ & $C_{12}$ & 0.8 & 0.2 & 0 & 0 & 0 \\
\hline$B_{13}$ & $C_{13}$ & 0 & 0 & 0.85 & 0.15 & 0 \\
\hline$B_{14}$ & $C_{14}$ & 0 & 0 & 0 & 0.34 & 0.66 \\
\hline$B_{15}$ & $C_{15}$ & 1 & 0 & 0 & 0 & 0 \\
\hline$B_{21}$ & $C_{21}$ & 1 & 0 & 0 & 0 & 0 \\
\hline$B_{22}$ & $C_{22}$ & 0 & 0.71 & 0.29 & 0 & 0 \\
\hline$B_{23}$ & $C_{23}$ & 0 & 0 & 0.78 & 0.22 & 0 \\
\hline$B_{24}$ & $C_{24}$ & 0.53 & 0.47 & 0 & 0 & 0 \\
\hline$B_{25}$ & $C_{25}$ & 1 & 0 & 0 & 0 & 0 \\
\hline$B_{31}$ & $C_{31}$ & 0 & 0 & 0.87 & 0.13 & 0 \\
\hline$B_{32}$ & $C_{32}$ & 0 & 0.59 & 0.41 & 0 & 0 \\
\hline$B_{33}$ & $C_{33}$ & 0 & 0 & 0 & 0.78 & 0.22 \\
\hline$B_{41}$ & $C_{41}$ & 1 & 0 & 0 & 0 & 0 \\
\hline$B_{42}$ & $C_{42}$ & 0.04 & 0.96 & 0 & 0 & 0 \\
\hline$B_{43}$ & $C_{43}$ & 0 & 0 & 1 & 0 & 0 \\
\hline$B_{51}$ & $C_{51}$ & 0 & 0.97 & 0.03 & 0 & 0 \\
\hline$B_{52}$ & $C_{52}$ & 0 & 0 & 0 & 0.06 & 0.94 \\
\hline
\end{tabular}
rate of industrial solid waste" are also very well. The fulfillment of "Wastewater emissions per ten thousand

\begin{tabular}{|c|c|c|c|c|c|}
\hline The first class indexes & Environmental protection & Resources utilization & Economic benefit & Human resource & Social contribution \\
\hline Comprehensive score & 0.1478 & 0.1665 & 0.2021 & 0.2186 & 0.2650 \\
\hline Result & Excellence & Excellence & Poor & Medium & Very poor \\
\hline
\end{tabular}
yuan RMB operating income", "Capital value-retaining and value-increasing rate" and "Donation rate to society" are not good enough.

2) The fulfillment of the first class indexes

It can be seen from Table 5 that the fulfillment of "En-

Table 4 The membership degree of the second class indexes.

Table 5. The evaluation result of the first class indexes. 
vironmental protection" and "Resources utilization" are excellence, "Economic benefit" is poor, "Human resource" is medium and "Social contribution" is very poor for WISCO in 2008, according to the maximum membership degree principle.

In a word, this paper constructed a set of enterprise social responsibility evaluation indexes system based on "Two-oriented society", which included of environmental protection, resources utilization, economic benefit, human resources and social contribution. And more second indexes were designed to reflect the characteristics of environmental protection and resources utilization, which can prominent the theme of "Two-oriented society". In the part of case analysis, WISCO was taken for example, and two-step fuzzy evaluation method was used to evaluate the social responsibility performance of in 2008 .

\section{Acknowledgements}

This research is supported by NSSF of China (Grant No. 09BJY015).

\section{REFERENCES}

[1] Q. Yang and D. Chen, "Society Responsibility Accounting Criterion," Audit \& Economy Research, Vol. 23, No. 2, 2008, pp. 56-59.

[2] A. Geva, "Three Model of Corporate Social Responsibility: Interrelationships between Theory, Research, and Practice," Business and Society Review, Vol. 113, No. 1, 2008, pp. 1-41.

[3] X. Li, "Construction of Index System of Enterprise Social Responsibility Performance in Chinese," Finance and Accounting Monthly, No. 24, 2008, pp. 11-12.

[4] T. L. Saaty, "The Analytic Hierarchy Process," McGraw Hill Inc., New York, 1980.

[5] J. Xu, "Comprehensive Evaluation of Casting Quality Based on the Modified Fuzzy Analysis," Foundry Technology, Vol. 28, No. 5, 2007, pp. 690-693.

[6] D. Li and P. Li, "Comprehensive Evaluation on Economic Benefit of Greenhouse Based on Revised AHP Analysis Method," Jiangsu Agricultural Sciences, No. 6, 2009, pp. 447-450. 